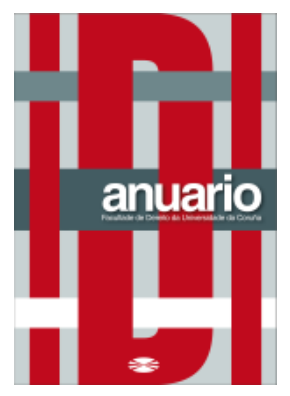

Anuario da Facultade de Dereito da Universidade da Coruña

Vol. 24 (2020), pp. 129-149

ISSNe: 2530-6324 || ISSN: 1138-039X

DOI: https://doi.org/10.17979/afdudc.2020.24.0.7464

\title{
SERVICIO PARLAMENTARIO DE CARRERA EN EL PODER LEGISLATIVO MEXIQUENSE. PARA EL FORTALECIMIENTO INSTITUCIONAL Y LA PROFESIONALIZACIÓN DE LA FUNCIÓN PÚBLICA
}

\section{PARLIAMENTARY SERVICE OF CAREER IN LEGISLATIVE POWER OF THE MEXICAN STATE. FOR THE INSTITUTIONAL STRENGTHENING AND PROFESSIONALIZATION OF THE PUBLIC FUNCTION}

\begin{abstract}
CARLOS MUÑIZ DÍAZ Investigador del Centro de Investigación en Ciencias Jurídicas, Justicia Penal y Seguridad Pública. UAEMex. Miembro del Sistema Nacional de Investigadores Nivel I https://orcid.org/0000-0003-4695-6385 dmcguitars1@gmail.com

YASÍ GONZÁLEZ MONROY Doctorante en Derecho Parlamentario UAEMex https://orcid.org/0000-0002-7218-6081 gmyasi@gmail.com

"Las leyes no son puros actos de poder, sino de sabiduría, de justicia y de razón. El legislador no ejerce la autoridad, sino un sacerdocio. No debe perder de vista que las leyes se hacen para los hombres y no los hombres para las leyes..."
\end{abstract}

Discurso preliminar Código Civil de Napoleón (PORTALIS, 2014)

Recibido: 31/07/2020

Aceptado: 21/09/2020 
Resumen: Siendo el Poder Legislativo del Estado de México una institución garante de la democracia, resulta necesario fortalecer su función, implementando un servicio profesional de carrera denominado Servicio Parlamentario de Carrera, que concentre a profesionales conocedores de la labor legislativa afines al derecho parlamentario, que den legitimidad a los actos de representación que tienen los legisladores, y que en un corto plazo se vea reflejado en el fortalecimiento institucional y la profesionalización de la función pública. Para esto es indispensable contar con personas especializadas en la materia, con una gran fortaleza cívica y un sentido común guiado, siempre, por la razón y la justicia.

Palabras clave: Derecho parlamentario, Servicio parlamentario de carrera, Poder legislativo, Profesionalización, Fortalecimiento institucional.

Abstract: As the Legislative Power of the State of Mexico is a guarantor of democracy, it is necessary to strengthen its function, implementing a professional career service called the Parliamentary Career Service, which brings together professionals who are familiar with legislative work related to parliamentary law, who give legitimacy to the acts of representation that the legislators have, and that in the short term it is reflected in the institutional strengthening and the professionalization of the public function. For this it is essential to have people specialized in the matter, with great civic strength and a common sense guided, always, by reason and justice.

Keywords: Parliamentary law, Parliamentary career service, Legislative power, Professionalization, Institutional strengthening.

Sumario: I. INTRODUCCIÓN. II. DERECHO PARLAMENTARIO. 1. Principios y prácticas parlamentarias. 2. Proceso Legislativo y Teoría de la Legislación. III. APOYO TÉCNICO LEGISLATIVO: 1. Servicio parlamentario de carrera. 2. Propuesta. IV. CONSIDERACIONES GENERALES. FUENTES DE CONSULTA.

\section{INTRODUCCIÓN}

El Poder Legislativo como máxima institución en el sistema democrático, es el encargado de representar a los ciudadanos y refleja su conformación y evolución a través del tiempo. Así, resulta entonces, ser la expresión más clara de la voluntad popular y se configura como el órgano más importante del sistema político. Sin embargo, el Poder Legislativo en el Estado de México ha experimentado un proceso de estancamiento que lo ha relegado a un plano en la vida pública en el que ha perdido parte importante de su poder. Cuestionado por algunos sectores de la ciudadanía, en algunos momentos satanizado por su relación de complicidad con el Poder Ejecutivo y en otros criticado por la falta de personal capacitado que apoya a los legisladores, ha puesto en riesgo la integridad de algunos sectores de la población, por no tener la capacidad de análisis y estudio en los asuntos que 
se presentan en el pleno y se turnan a las Comisiones Legislativas para su dictamen, aunado al importante rezago legislativo, que sigue siendo tarea pendiente.

Uno de los grandes retos que hoy enfrenta el Legislativo Mexiquense, es legitimar su poder, basado en su esencia primordial como representante de los intereses del pueblo y vehículo para la solución de problemas que aquejan a la sociedad. Su nueva conformación con mayoría de ideología social, opuesta al partido político al que pertenece el Poder Ejecutivo en turno, resulta ocasión especial para imponerse como un verdadero contrapeso, y además, como un tomador de decisiones que más allá de compromisos ideológicos para posicionarse como un poder autonómico con decisiones de alto impacto que beneficien a los mexiquenses, deberá legislar estratégicamente para consolidar el desarrollo del Estado y cambiar la percepción ciudadana.

Para ello, sin menospreciar la función del legislador, en ésta ocasión quisiera enfocarme en las personas que conforman su equipo de trabajo, a sus asesores, profesionales que dedican su labor a la investigación, a la elaboración de argumentos y al apego estricto de la técnica legislativa. Es decir, a aquellos cuerpos técnicos que hacen posible que un legislador tenga elementos y herramientas sobre los temas que se desarrollan al interior de la legislatura deben fortalecerse e implementar un servicio de apoyo técnicojurídico experto, de carácter permanente y en constante actualización, capaz de proveer a los legisladores la información específica, necesaria y pertinente, de manera profesional, técnica e intelectual que requieren para estar en posibilidad de plasmar en una propuesta legislativa aquello que, a su juicio y producto del ejercicio de su representatividad, garantizará dos importantes vertientes, la primera permitirá que el Poder legislativo se fortalezca y la segunda profesionalizará la función pública.

Con éstas dos vertientes, el Poder legislativo no sólo será formador de talentos y expertos en distintas materias dentro del derecho parlamentario, sino que dará excelentes resultados en todas y cada una de sus actuaciones, siendo una de ellas, la más importante, legislar.

Es importante tomar en cuenta que el asesor, es decir, el apoyo técnico legislativo, debe cubrir con un perfil profesional específico, con un dominio general en temas de índole social, presupuestal y lo jurídico. Dicho apoyo, debe estar preparado como base principal en la Licenciatura en Derecho, ya que su labor esencial será la elaboración, análisis y estudio de las leyes, para esto es importante que tenga especialización en Derecho Parlamentario y Constitucional, ya que son base fundamental para el trabajo legislativo. Éste se debe conducir con objetividad y ética, con juicios acordes a la realidad social, pensando en el bien común y anteponiendo la moral para de ejecución de las leyes, con la firme convicción de construir un marco legal estable. Es necesario que sean capaces de detectar incongruencias y vacíos legales, para proponer sus modificaciones, que tengan la capacidad de negociación y cabildeo para mediar y obtener el mejor resultado para la sociedad.

En términos generales la función del asesor, será entregar un producto terminado, resultado de la comparación análisis y depuración de la investigación en temas legislativos para el fortalecimiento institucional y la profesionalización de la función pública. 


\section{DERECHO PARLAMENTARIO}

Desde la antigua Grecia Platón, en el más extenso de sus diálogos “La República”, proponía una visión utópica del gobierno del Estado, representaba en su obra un modelo de sistema parlamentario en el que describe a los sabios como principales responsables del poder, teniendo como objetivo transformar la política en la más noble de las prácticas, donde los filósofos llevaban a cabo la labor de aconsejar y proponer leyes y acciones, regidas siempre por la razón y direccionadas a la armonía social.

El primer sistema parlamentario formal, surge en Inglaterra, en el siglo XII, desde su concepción ha sufrido cambios severos, a través de una constante evolución histórica desarrollada a lo largo de distintas formas de gobierno, en principio, con un régimen que se caracterizaba esencialmente por un Rey que gobernaba en su totalidad, tenía el poder absoluto y la legitimidad popular era débil. Tiempo después surge la figura política del Primer Ministro personaje que con ayuda de un gabinete dirige el gobierno, requería la confianza de las asambleas o Cámara de los Comunes, cuya supremacía se afirma, por el hecho de representar a las clases que poseen el poder económico, con cambios paulatinos hasta lo que ahora conocemos como democracia.

Para inicios del siglo XVIII en la Gran Bretaña, el modelo democrático se encontraba plenamente establecido y funcionando de manera efectiva, pioneros en derecho parlamentario, dan inicio a lo que actualmente conocemos como división de poderes, donde el parlamento es representado en nuestro país como el poder legislativo, garante de la representación popular, encomendado a estructurar de manera dúctil las reglas y mecanismos protectores de derechos y obligaciones de conformidad con la realidad social.

La premisa del derecho parlamentario, siendo parte del derecho constitucional, implica entonces, todo aquello que se origina al interior del Poder Legislativo y permanece en cada acto. Para Santaolalla es "el conjunto de normas que regulan la organización y funcionamiento de las cámaras parlamentarias, entendido como órganos que sumen la representación popular de un Estado constitucional y democrático de Derecho y el ejercicio de sus funciones supremas” 1 .

Pedroza lo define como "el conjunto de normas que regulan la organización y funcionamiento de las cámaras como órganos que asumen la representación popular en un Estado constitucional y democrático de derecho, y no es suficiente que se le denomine Parlamento, sino que lo esencial es que dicha institución encarne libre y democráticamente la voluntad popular"².

\footnotetext{
${ }^{1}$ Santaolalla López, F., Derecho Parlamentario Español. Madrid, Espasa Calpe, 1990, p. 30.

2 Pedroza De La Llave, S.T., Las fuentes formales del derecho parlamentario y su normatividad constitucional en México. Cuest. Const. [online]. 2012, n.26 [citado 2020-02-23], pp.169-220. Disponible en: $<$ http://www.scielo.org.mx/scielo.php?script=sci_arttext\&pid=S140591932012000100006\&lng=es\&nrm=iso>. ISSN 1405-9193.
} 
Berlín, refiere que es el “conjunto de normas con que son recogidas las actividades internas de las asambleas legislativas de los Estados, en lo referente a su organización, funcionamiento, facultades, deberes, privilegios para sus miembros y relaciones entre grupos políticos que lo integra”3.

Tosi asegura, que al derecho parlamentario “corresponde la regulación no sólo de los procesos y procedimientos legislativos y de los organismos o estructuras que intervienen en ellos, sino de una muy vasta y compleja red de relaciones políticas de un régimen, todas aquellas en las cuales el parlamento sea actor o interlocutor" ${ }^{4}$.

Autores como Alonso de Antonio afirman que es "aquella parte del Derecho Constitucional que se ocupa del análisis de lo referente al parlamento”, además de precisar ciertas características como:

1) ...“es un derecho políticamente comprometido, porque sólo es admisible su existencia en regímenes democráticos que garanticen la representatividad de los ciudadanos a través de un Parlamento;

2) es un derecho generalmente flexible, porque ante el cambio de circunstancias y la posible ausencia de regulación necesaria al efecto, se motiva una respuesta rápida de los órganos parlamentarios competentes;

3) normalmente es una producción, debido a la autonomía funcional del Parlamento que implica la autonomía de regulación;

4) es fruto del consenso, debido a que sus normas deben ser resultado del acuerdo de todas las fuerzas del Parlamento, sin imposición de una sobre otras; $\mathrm{y}$

5) es revisable o controlable, pues la justicia constitucional vela por la constitucionalidad de los reglamentos, de las resoluciones generales de los órganos de dirección” 5 .

Entonces, podemos decir que el derecho parlamentario puede ser considerado una disciplina, que como lo afirma Cervantes "estudia las reglas de organización y el funcionamiento de las asambleas legislativas democráticas, o bien el conjunto de normas que regulan la organización y el funcionamiento del Poder Legislativo, en tanto asamblea representativa, así como los deberes y prerrogativas de los legisladores”6.

El Derecho Parlamentario tiene como “objeto de estudio al órgano investido de la representación social de un Estado, las normas que lo regulan y la amplia serie de

\footnotetext{
${ }^{3}$ Berlín Valenzuela, F., Derecho Parlamentario. México, Fondo de Cultura Económica, 2000, p. 33.

${ }^{4}$ Tosi, S., Derecho Parlamentario. México, Miguel Ángel Porrúa, 1996, p. 6.

${ }^{5}$ Alonso de Antonio, J.A. y Alonso de Antonio, A.L., Introducción al Derecho Parlamentario, Madrid, España, Dykinson, 2002, pp. 22-23.

${ }^{6}$ Cervantes Gómez, J.C., Derecho Parlamentario, Organización y Funcionamiento del Congreso, México, Serie Roja, 2012, p. 5.
} 
disposiciones que rigen el comportamiento de los sujetos que intervienen en los diversos procesos legislativos"7. Y como lo afirma Bátiz, "su finalidad es que a través del cumplimiento de sus normas se alcance el resultado que se busca, la formación de buenas leyes y la toma de decisiones colegiadas, que sirvan para facilitar la convivencia de todos"8.

Dentro del derecho parlamentario, encontramos que se rige por normas escritas, una de ellas y la más importante, la Constitución, después la respalda su ley orgánica y reglamentos internos, pero también por otras, que se adecuan a cada parlamento o legislatura, son prácticas heredadas, acciones por costumbre, que definen la labor legislativa.

\section{Principios y prácticas parlamentarias}

En el Derecho Parlamentario las funciones legislativas están integradas por los principios parlamentarios que son el fundamento que regula y da origen a las prácticas parlamentarias. Actúan como señalamientos que permiten al legislador, saber qué debe hacer o dejar de hacer. Se convierten de este modo, en una guía de acciones, deberes y obligaciones legislativas, que ayudan a crear leyes e identificar vacíos legales en la normatividad vigente, Ordaz dice que "incluso cuando estas, no están previstas en el ordenamiento jurídico, deben de entrar las prácticas parlamentarias para solucionar estos vacíos legales”.

Para resaltar dicha importancia, hablaremos de cuatro principios básicos, que exponen una visión ética de la labor legislativa:

a) El principio representación, se encuentra en la base misma del parlamentarismo, implica la confianza ciudadana, el voto empeñado en una persona para llevar al más alto nivel la toma de decisiones, basado en el interés y bien común. Los legisladores no actúan para sus propios fines sino que lo hacen en nombre de otros, son representantes y su ser implica la existencia de personas diferentes a ellos mismos que son sus representados; Como plantea Bátiz, "por el principio de la representación, las acciones y decisiones del representante producen efectos en las vidas, personas y bienes de los representados" ${ }^{10}$.

b) El principio de libertad, recae en el cuerpo colegiado en su conjunto, con la prolijidad de facultades y obligaciones que la Constitución y las leyes le confieren. Este principio radica en que los legisladores, al momento de actuar cumpliendo el carácter de representantes populares, lo hagan con plena libertad, declarando sus opiniones para la toma de decisiones colectivas que permitan conocer la viabilidad de las propuestas legislativas, expresadas con su voto personal.

\footnotetext{
${ }^{7}$ Garita, A., La Práctica Parlamentaria, México, Senado de la República, 2016, p. 10.

${ }^{8}$ Bátiz Vázquez, B., Teoría del Derecho Parlamentario. México, Oxford, 1992, p. 46.

${ }^{9}$ Ordaz Sánchez, G., La evolución de los Principios Parlamentarios y su vinculación con las Prácticas Parlamentarias. Representación, Derecho a la Información e Igualdad, México, Instituto de investigaciones Jurídicas, 2017, p. 34.

${ }^{10}$ Bátiz, op. cit., p. 48.
} 
c) El principio de información, es el que les garantiza conocer todo lo referente a los proyectos y temas legislativos, para que estén preparados en los trabajos que se llevan a cabo en la Legislatura y les permita emitir opinión y tomar una decisión al respecto. Este principio se hace efectivo con los apoyos técnicos, quienes ayudan a los legisladores dotándolos de información para intervenir en las Comisiones, en las mesas de trabajo, en reuniones de grupo parlamentario y en el Pleno. La información representa poder, aquel legislador o grupo parlamentario que cuente con la mejor información, es decir, información verídica, sustentada, fundamentada, comparada y actual proporcionará mejores argumentos para cumplir con el mandato primordial de la justicia, hacer mejores leyes para el bien común.

d) El principio de igualdad, es aquel que mantiene el equilibrio entre los legisladores, éste garantiza la fórmula perfecta de uno es igual a uno, un legislador, un voto. Como lo expresa Bátiz, “el principio se expresa con la idea de que quienes integran un cuerpo legislativo son entre sí pares o iguales y ninguno tiene preeminencia o superioridad respecto de los demás”11.

Estos principios son alianza perfecta con las prácticas parlamentarias, ya que cuando hablamos de prácticas parlamentarias nos referimos al conjunto de actos, que normalmente no están regulados de manera escrita, que se van llevando a cabo por el órgano legislativo a manera de respuesta para adoptar una postura sobre ciertas conductas, bajo criterios y procedimientos basados en los usos y costumbres para confirmarse como una facultad y obligación a cargo del órgano legislativo.

El vocablo compuesto se refiere a las prácticas y usos comunes en el ámbito parlamentario que son realizados por sus integrantes. ${ }^{12}$ Las prácticas parlamentarias, entonces, son definidas como aquellos "usos y costumbres en que se sustentan los procedimientos y formalidades aplicables al régimen interno de las actividades políticolegislativas del Congreso" $13 \mathrm{y}$, por ende, constituyen una fuente del derecho parlamentario o legislativo.

Estas prácticas, son el precedente de la normatividad interna que regula el trabajo de la Legislatura, establecidas en la Constitución local, la ley orgánica y el reglamento. Son los ordenamientos que indican las facultades y atribuciones, la organización y el funcionamiento, el tipo de órganos y dependencias que la integran, los grupos parlamentarios, la mecánica y distribución del trabajo, el proceso legislativo, la mesa técnica, entre otros.

Cuando dichos ordenamientos no contienen expresamente alguna circunstancia o situación, los líderes de los grupos parlamentarios, conformados en el máximo órgano de la

${ }^{11}$ Bátiz Vázquez, B., Ética Jurídica (segundas jornadas) Javier Saldaña (coord) México, UNAM, Instituto de Investigaciones Jurídicas, Editorial Flores, 2016, p. 133.

${ }^{12}$ Garita, A., op. cit., p. 11.

${ }^{13}$ Madero Estrada, J.M., Diccionario Legislativo, Tepic, Universidad Autónoma de Nayarit, 2000. 
Legislatura, la Junta de Coordinación Política, llegan a acuerdos y son estos los que avalan cualquier acción o decisión para el rumbo de la Legislatura.

Dichos acuerdos, dice Cabada "se nutren esencialmente del elemento consuetudinario, objetivado en el reconocimiento de los usos y prácticas parlamentarias; son el resultado de las negociaciones entre las diversas fuerzas políticas”, ${ }^{14}$ constituidas en el Poder Legislativo, las cuales son normadas por reglas escritas, pero muchas otras por reglas establecidas de manera política.

\section{Proceso Legislativo y Teoría de la Legislación}

En el proceso de producción legislativa, tenemos que el conjunto de fases sucesivas y el conocimiento especulativo de estricta aplicación, se convierten en sinergia perfecta. El proceso legislativo, conformado de fases determinadas en la Constitución y las propias leyes internas de cada Congreso, son el camino que se debe seguir para producir una ley. Entonces, la iniciativa de ley se convierte por sí, en un intento de racionalizar los intereses o conflictos de una sociedad. "El procedimiento legislativo es conceptualizado como la serie ordenada de actos que deben realizar los órganos del gobierno facultados para ello, a fin de elaborar, aprobar y expedir una ley o decreto"15.

El proceso legislativo es el camino para modificar, actualizar o crear una norma jurídica, pues este se convierte en instrumento a través del cual el órgano representativo del pueblo, expresa su voluntad legislativa.

En el estado de México, el proceso legislativo consta de las siguientes etapas:

${ }^{14}$ Cabada Huerta, M. La Naturaleza del Acuerdo Parlamentario, Revista Quórum Legislativo, No. 88, enero-marzo de 2007. Centro de Estudios de Derecho e Investigaciones Parlamentarias de la Cámara de Diputados del Congreso de la Unión, pág. 116.

${ }^{15}$ Carbonell, M. (coord.), Diccionario de derecho constitucional, $2^{\text {a }}$ ed., México, Porrúa-UNAM, 2005, p. 494; y Fernández Ruiz, J., Poder legislativo, México, Porrúa-UNAM, 2003, p. 428. 


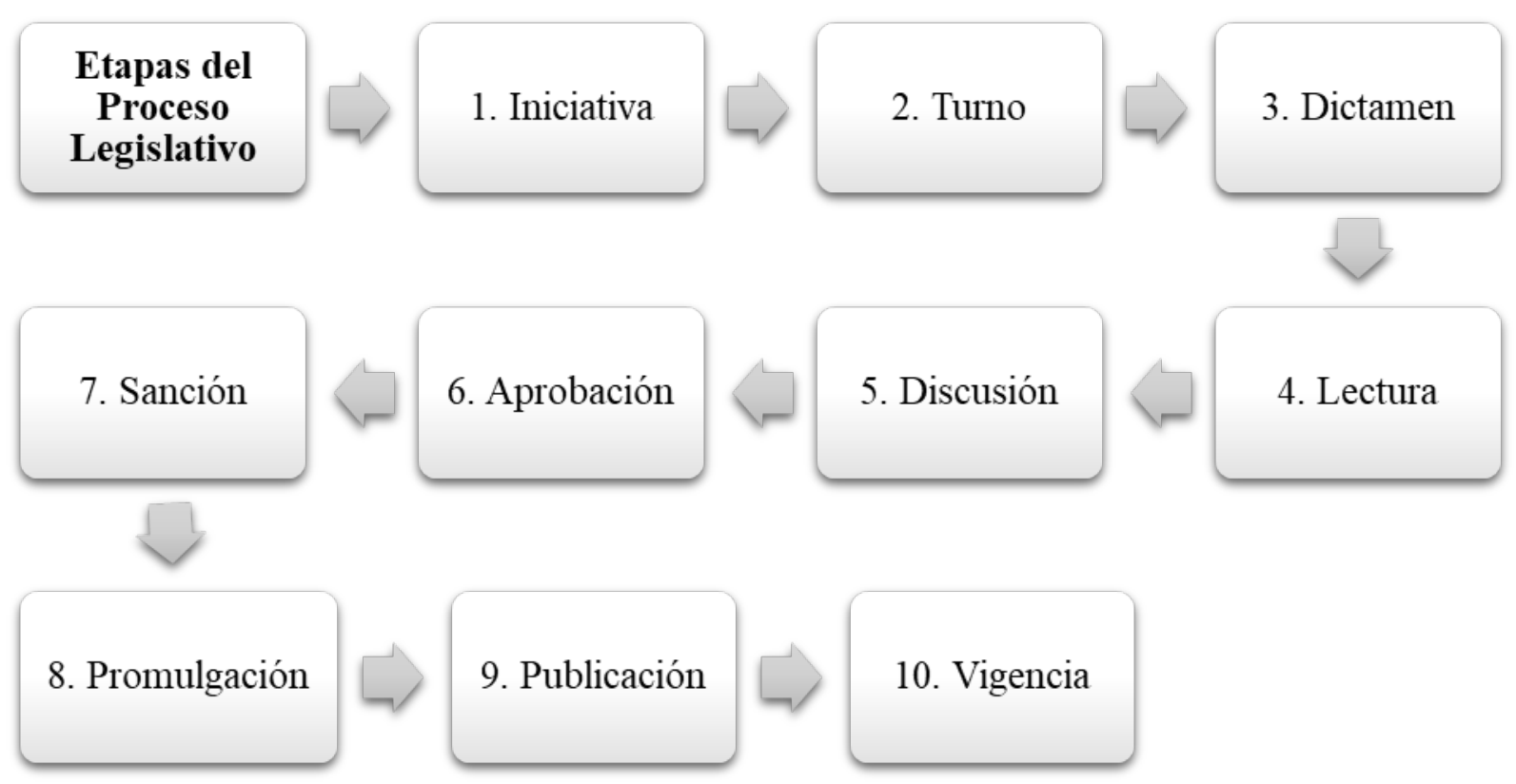

1.- La iniciativa.- es la propuesta de los sujetos que por Ley tienen derecho a presentar modificaciones, adiciones o creación de leyes, para el caso del Estado de México, la Constitución Política del Estado Libre y Soberano de México establece que quienes tienen el derecho de iniciar leyes y decretos son: Gobernador del Estado, diputados, Tribunal Superior de Justicia, Ayuntamientos, Ciudadanos del Estado, Comisión de Derechos Humanos Estatal en su materia y la Fiscalía General de Justicia.

2.- Turno.- una vez que ingresa y se presenta en el Pleno, se turna para su análisis y estudio a la Comisión o comisiones en la materia.

3.- Dictamen.- es el resultado de la valoración de la iniciativa.

4.- Lectura.- es cuando se lee ante el pleno el dictamen y este emite su voto para el trámite correspondiente.

5.- Discusión.- los legisladores emiten su opinión sobre el tema, con argumentos sólidos, fundados y motivados para defender su dicho.

6.- Aprobación.- mediante la votación del pleno, dependiendo el tipo de iniciativa, es decir, si requiere mayoría simple o dos terceras partes, se decide por mayoría o unanimidad de votos su aprobación.

7.- Sanción.- es la aceptación de una iniciativa por parte del Poder Ejecutivo o en su caso emite las modificaciones pertinentes.

8.- Promulgación.- es el acto formal por el cual el Poder Ejecutivo aprueba y dispone publicar un proyecto de ley. 
9.- Publicación.- es el acto por virtud del cual el ejecutivo lleva al conocimiento de los habitantes una Ley votada y promulgada, la Ley es conocida por todos.

10.- Vigencia.- Es cuando la Ley entra en vigor y comienza a surtir efectos en la población.

En el caso de la Teoría de la Legislación, ésta tiene como objeto de estudio, el amplio ámbito que abarca desde el momento de asumir la decisión política, hasta el instante en el que esta se concretiza mediante su incorporación e impacto al ordenamiento jurídico en forma de ley. Es decir, el legislador en su calidad de representante del pueblo lleva a la altísima tribuna las necesidades de la sociedad, sin embargo, en este lapso de tiempo, donde se recoge la inquietud y se elabora el documento para su presentación en pleno. El personal que asesora al legislador es el encargado de preparar la información, de vigilar el tránsito de la voluntad política, hasta culminar en una norma con rango de ley.

Lo más importante de esta teoría radica en la necesidad fundamental de racionalizar la presentación de iniciativas que tengan elegibilidad y sean viables, mayor calidad en el marco normativo y menor cantidad de leyes sin ejecución, ya que en su elaboración deberán estar presentes elementos que permitan una reflexión más profunda sobre las causas y la justificación de su ejecución, que de ser aprobadas impliquen impacto directo en la sociedad. Mora-Donatto expresa que "dicha teoría no pierde de vista que el problema de la elaboración de las leyes no es, ni mucho menos, sólo un problema de buena redacción sino incluso una exigencia para volver efectivos los principios de legalidad y seguridad jurídica en que se inspira un genuino Estado de Derecho" ${ }^{\text {" }}$.

Además de lo anterior, es imprescindible considerar el contexto sociopolítico haciendo un balance de las perspectivas y un análisis del costo beneficio, "esta reflexión sobre los principios de la buena legislación y los efectos sociales de las normas jurídicas, describen la ética jurídica y la visión humanista, como una de las actividades más características de la sociología del derecho" ${ }^{17}$.

Es importante resaltar que el proceso de producción legislativa es una herramienta indispensable para ensamblar todas aquellas materias necesarias para abordar las conductas sociales $\mathrm{y}$ entonces formular restricciones normativas $\mathrm{o}$ garantizar prerrogativas ciudadanas, adecuadas a la realidad estatal y nacional de conformidad con la planeación de desarrollo en todos los aspectos.

Hacer una planeación del proceso legislativo resulta útil para abordar todas aquellas situaciones que conlleva un parlamento, la pluralidad de ideologías, la realidad

16 Mora-Donatto, C., Teoría de la Legislación y Técnica Legislativa. México, Instituto de Investigaciones Jurídicas UNAM, 2012, p. 5.

17 Arias-Schreiber, F., \& Peña Jumpa, A. (2015). La nueva teoría de la legislación. IUS ET VERITAS, 24(51) 196-206.

Recuperado

$a$

partir

de

http://revistas.pucp.edu.pe/index.php/iusetveritas/article/view/15695. 
social y las acciones de la federación son elementos que obligan al cumplimiento voluntario de cada uno de los legisladores para la efectiva coacción en la ejecución de su eficiencia.

Se debe de considerar para la creación actualización, modificación y armonización de leyes con aplicación efectiva que garanticen derechos, la teoría de la legislación a cargo de personal calificado, especialista en la materia.

Como lo afirma Mora-Donatto, debemos de considerar que dicha teoría nos ayudará a determinar cuándo debe crearse una Ley, es evidente que no siempre la solución a un problema será un texto legal, y describe cuatro etapas que nos ayudan a determinar si un problema necesita la creación de un ordenamiento jurídico, divididas en tres fases: prelegislativa, legislativa y poslegislativa ${ }^{18}$.

- $\quad$ Primera etapa (prelegislativa): es cuando el legislador en campaña o trabajo en su distrito hace la labor de consultar con sus vecinos las problemáticas que aquejan su entorno o bien, cuando el problema social se amplía a un problema estatal o extraestatal.

- Segunda etapa (prelegislativa): es cuando el legislador lleva dicha problemática a su equipo de trabajo y este elabora un diagnóstico de evaluación para determinar la necesidad de crear una Ley o bien exhortar al ejecutivo para la ejecución de una política pública.

- Tercera etapa (legislativa): el equipo del legislador ha redactado una iniciativa con los elementos técnicos necesarios para presentar una iniciativa de Ley y someterla a discusión y aprobación del Pleno.

- Cuarta etapa (poslegislativa): se evalúan los efectos de la Ley y su impacto en la solución del problema que le dio vida.

\section{APOYO TÉCNICO LEGISLATIVO}

Dentro de la labor legislativa, podemos encontrar como primer referente al actor político, sin embargo, para éste caso, nos centraremos en la importante labor del asesor institucional. Como lo afirma Mora-Donatto "el primero, desarrolla una actividad constitucional y legalmente relevante para el sistema representativo y democrático rigiéndose exclusivamente bajo el criterio de oportunidad política. Mientras que el asesor institucional, despliega una actividad de extraordinaria importancia al servicio de las funciones parlamentarias"19.

\footnotetext{
${ }^{18}$ Mora-Donatto, C., op cit., p. 13.

19 Mora-Donatto, C., Urge rediseñar el servicio civil de carrera del Congreso mexicano. Cuest. Const. [online]. 2008, n.19 [citado 2019-12-28], pp.173-209. Disponible en: <http://www.scielo.org.mx/scielo.php?script=sci_arttext\&pid=S140591932008000200007\&lng=es\&nrm=iso>. ISSN 1405-9193.
} 
Cuando hablamos de apoyo técnico legislativo, nos referimos a las personas que acompañan las funciones parlamentarias de los representantes, los asesores que se dedican a proveer información, elaborar iniciativas o puntos de acuerdo, diagnósticos, dictámenes, fichas técnicas o análisis de temas que se desahogan en las comisiones legislativas, son quienes realizan toda la investigación para conocer y analizar los problemas y sus soluciones, tienen la gran responsabilidad de convertir una necesidad, problema o inquietud social en un proyecto de ley, denominado iniciativa.

La variedad y complejidad de los temas abordados por los legisladores requiere de un cuerpo de especialistas que den mayor certeza, conocimiento y profundidad, y ofrezcan mejores respuestas a las problemáticas. Por ello, crear espacios donde se concentren "expertos en cada una de las áreas a legislar que pueden y deben orientar a los grupos parlamentarios en la elaboración de iniciativas y en su propia discusión, a fin de racionalizar la discusión y el trabajo legislativo”, ${ }^{20}$ fortalecería sin duda a la Institución en sí misma.

Los espacios ocupados por los apoyos técnicos legislativos (los asesores), son de carácter eventual, cambian durante la legislatura vigente y en el mejor de los casos, permanecen el tiempo que dura la Legislatura. Carecen de experiencia y su perfil académico no logra hacerle frente a las tareas del parlamento. Esto debilita la credibilidad social a la hora de calificar el trabajo legislativo y pone en riesgo la estabilidad institucional.

\section{Servicio Parlamentario de Carrera}

Para situarnos en el concepto, como lo describe Pardo, el servicio "de carrera es una forma de gestionar los recursos humanos, para formar servidores públicos cuyo compromiso sea con el interés común, sin consideraciones políticas de grupo o partido, basada en el mérito, la imparcialidad y la igualdad de oportunidades” ${ }^{21}$.

La profesionalización es el elemento más importante dentro de la fórmula perfecta que garantiza legitimidad en los actos legislativos, seguridad jurídica y permanencia laboral, privilegiar la experiencia, bajo la garantía de un sistema de servicio de carrera legislativa, fortalecería la labor del legislador y el beneficio social.

Además, Pardo argumenta que implementar el servicio parlamentario de carrera, constituiría "un instrumento fundamental para fortalecer la aptitud y competencia profesional de la función pública, como un medio de alto valor incuestionable que propicia un mejoramiento sustancial en la calidad del ejercicio de los recursos públicos” ${ }^{22}$.

20 Valencia Escamilla, L., Élites parlamentarias y profesionalización legislativa en México. El Cotidiano [en linea]. 2009, (155), 69-76 [fecha de Consulta 13 de Enero de 2020]. ISSN: 0186-1840. Disponible en: https://www.redalyc.org/articulo.oa?id=32512745008.

21 Pardo, M.C., El Servicio Profesional de Carrera en México: De la Tradición al Cambio. Foro Internacional [en linea]. 2005, XLV(4), 599-634[fecha de Consulta 2 de febrero de 2020]. ISSN: 0185-013X. Disponible en: https://www.redalyc.org/articulo.oa?id=59911177002.

${ }^{22}$ Pardo, M.C., op cit. 
Una de las premisas de la representación popular es velar por el bien común, proteger los derechos de todas las personas, impulsar el crecimiento y desarrollo económico, proteger el estado de derecho, transparentar la función pública y garantizar la rendición de cuentas, entre otros, por ello, contar con un equipo plural de profesionales técnico-jurídicos expertos en la materia, otorgaría claramente eficiencia y eficacia que causen un óptimo resultado en los objetivos institucionales y en el sentir social.

En el Estado de México, la transformación del Poder Legislativo está en curso, sin embargo, sigue siendo una tarea pendiente la profesionalización de la función pública.

No debemos dejar de observar, que dicha transformación, depende de la voluntad política y que en muchas ocasiones se enfrenta resistentemente al cambio, asociada a grupos de interés. Sin embargo, un buen manejo de la conciliación y la convergencia, se puede traducir en políticas eficaces y sostenibles para el proyecto de profesionalización legislativa. Por ello, como lo afirma Máttar "la institucionalidad y la voluntad política son dos condiciones necesarias y casi suficientes para la implementación duradera y sostenible de las acciones de profesionalización del servicio público"23.

Con base en el mérito y la igualdad de oportunidades, bajo un proceso generador de servidores públicos profesionales, honestos y efectivos, el fortalecimiento institucional, es decir el equilibrio perfecto entre la administración, el servicio público, la representación y el Estado de Derecho, se dará de manera sucesiva, en el engranaje de la maquinaria legislativa, en la parte que corresponde a la producción de leyes, se estará dando un paso agigantado, soslayando las malas prácticas o los cotos de poder, anteponiendo la ética parlamentaria.

\section{Propuesta}

Crear un servicio parlamentario de carrera que concentre a profesionales de la materia que se mantengan en constante actualización y capacitación, bajo estándares de permanencia basados en la evaluación y productividad, seleccionados mediante un mecanismo transparente y democrático que fortalezca la función pública. Profesionales capaces de emitir opiniones técnico-jurídicas basadas en conocimientos reales. Con la mejor información científica, técnica, presupuestal, nacional e internacional, para que así, los tomadores de decisiones -los legisladores- sean capaces de encontrar y conciliar con sus pares lo que mejor convenga a sus representados y el impacto que éstas decisiones puedan tener en la sociedad.

Para esto es necesario que el asesor, cumpla con un perfil especifico que tenga la capacidad de crear leyes desde su estructura gramatical y ortográfica, que sean claras y objetivas; que conozca del proceso legislativo, de técnica jurídica, de presupuesto, de impacto social y ambiental, de competencias y jurisdicción. Debe contar con una formación profesional específica y por último, siendo el elemento más importante debe de tener una moral ética guiada por la razón y el bien social.

${ }^{23}$ Máttar, J., Desafíos de un buen gobierno: La profesionalización de la función pública. Tepoztlán, Centro Tepoztlán Víctor L. Urquidi, AC., 2018, p. 16. 
A continuación, hago una propuesta del perfil profesional que considero debe cumplir el asesor legislativo:

- Licenciatura en Derecho

- Posgrado en materias afines, de preferencia en Derecho Constitucional o Parlamentario

- Experiencia de por lo menos dos legislaturas

- Buena presentación

- Expresión oral y corporal en público

- Conocimientos en redacción, retórica y argumentación jurídica

- Capacidad de conciliación, negociación y mediación

- Habilidad en investigación

- Manejo de TIC's (tecnologías de Información y Comunicación)

- Experto en proceso y técnica legislativa

- Liderazgo y capacidad de manejo de personal

- Disposición y capacidad de trabajar bajo presión de manera eficiente

- Deseo y compromiso de actualización y capacitación

Es importante, considerar al asesor legislativo como la herramienta humana capaz de emitir opiniones veraces que respalden la decisión del representante social, el actor principal siempre será el legislador, ya que este cumple con el mandato Constitucional y es legitimado con el sufragio efectivo.

El técnico profesional de apoyo debe contar con un equipo a su cargo que le ayude a la investigación, quienes se estarán formando para concursar en un futuro el cargo del servicio parlamentario de carrera.

La siguiente figura representa la propuesta de organigrama 


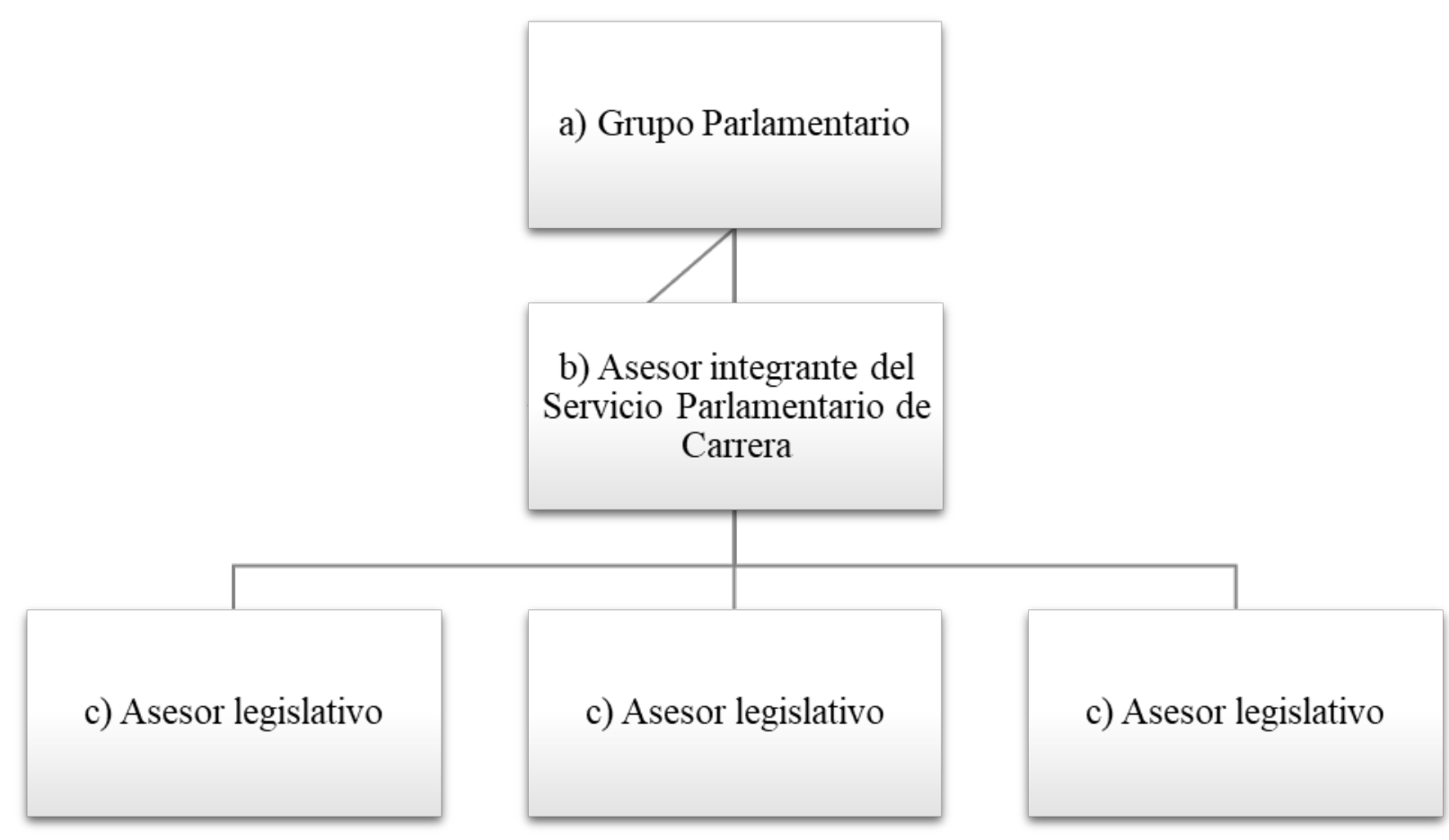
partido político.

a) El grupo parlamentario conformado por legisladores afines a un

b) El Asesor o asesores del Servicio Parlamentario de Carrera asignados al grupo parlamentario de conformidad con el número de integrantes. Será el encargado de guiar y coordinar la investigación, elaborará el documento final bajo principios de elegibilidad y viabilidad, con estricto orden gramatical y ortográfico que cuenten con la adecuada técnica y teoría legislativa, así como también realizará el análisis del impacto de riesgo y su posible solución. Este asesor tendrá la responsabilidad de tener toda la información para poder proporcionarla en caso de que sea requerida por el grupo parlamentario.

c) Asesor legislativo es quien será el apoyo encargado de la investigación para recabar datos de impacto económico, social, ambiental, datos duros, cifras, derecho comparado, a su vez se estará capacitando para su posible postulación al puesto de asesor integrante del servicio parlamentario de carrera.

Para garantizar la estabilidad jurídica del servicio parlamentario de carrera, es necesario modificar la Ley Orgánica del Poder Legislativo del Estado de México, crear el reglamento específico, emitir convocatoria, reclutar y capacitar, cabe mencionar que, la selección del personal debe ser mediante exámenes competitivos bajo un esquema de neutralidad política, destacando los conocimientos en la materia con base de derecho o afines con especialidad en parlamento, además de proteger el mérito basado en imparcialidad e igualdad de oportunidades, introducir a la función pública fundamentos éticos para lograr una actitud y comportamiento honorable, como un conjunto de reglas que 
administren y desarrollen al personal para la función pública y que estos respondan con eficiencia y eficacia al arte de elaborar leyes que correspondan a las demandas que la sociedad plantea por conducto de los legisladores.

\section{CONSIDERACIONES GENERALES}

En el Estado de México tenemos dificultades para producir leyes, no hablo de la composición política, ni de las ideologías o el color que abandere la mayoría, sino de aquellos problemas que derivan por sí, de un sistema jurídico complejo, aunado a la falta de conocimiento que se aprecia a menudo, como la imprecisión, la tergiversación, la contradicción y la inconsistencia de los proyectos que por cierto, muchos de ellos, son hoy ley vigente.

En la práctica, en el Poder Legislativo, a pesar de su nueva conformación, se siguen presentando violaciones a la ética parlamentaria, por ejemplo:

- La representación se ve afectada por los intereses de grupos con encomiendas ad doc que dejan de lado el interés social o de sus representados.

- La disciplina parlamentaria, la cual consiste en someterse a la decisión e ideología del partido, congela en automático la opinión personal de los legisladores que integran el grupo parlamentario, ya que tendrán que votar a favor o en contra de acuerdo a los intereses del partido.

- La información llega a cuenta gotas a los legisladores, normalmente se distribuye en el momento que se lleva a cabo la reunión de trabajo o comisión, por lo que resulta casi imposible recabar datos que permitan que el legislador emita una opinión fundada y motivada.

- La situación de desigualdad entre los iguales, es decir, los coordinadores son quienes pactan los acuerdos y quienes deciden por el resto de sus compañeros de grupo parlamentario, en ocasiones esto facilita la negociación política, sin embargo, vulnera la función política los demás legisladores.

En materia de trabajo legislativo en nuestro país, el avance ha sido mínimo, la mayoría de los legisladores no cuentan con equipos preparados para dicha labor, los puestos son asignados a personas por cuestiones de cuotas de campaña, clientelismo o compadrazgo. Debido a la falta de ética en el proceso legislativo, la toma decisiones apresuradas, la escaza información amplia, oportuna y certera de los temas a resolver, implica la aprobación de iniciativas que aunque se promulguen, no resolverán los problemas sociales o serán tan complejas que jamás podrán ser utilizadas. Además de los vicios e irregularidades que repercuten directamente en la certeza del derecho poniendo en tela de juicio la seguridad jurídica.

Lamentablemente, esto implica que el Poder Legislativo, no sea, el contrapeso que requiere la democracia en nuestro Estado, porque quienes sí cuentan con este tipo de apoyo 
técnico especializado, son los juristas del Poder Ejecutivo y son ellos quienes se convierten en la práctica, en los verdaderos legisladores.

Garantizar la división de Poderes en un estado democrático, también implica que las funciones de cada poder se realicen de manera satisfactoria a su función. En este caso el Poder Legislativo, como ente representante de la sociedad, tiene la función de crear leyes, para así, establecer un marco jurídico de acuerdo a las necesidades del Estado y de la sociedad en su conjunto.

Por ello, implementar el servicio parlamentario de carrera garantiza que la producción de leyes se realice de una manera metodológica que contemple todos los elementos necesarios técnicos y jurídicos, que se adapten a la realidad y a las necesidades de la sociedad, que sean posibles de ejecución y que presupuestalmente estén respaldadas, para que quienes toman las decisiones políticas, tengan los elementos ideales para emitir su aprobación o no.

Es importante que una Ley cuente con aspectos específicos que puedan asegurar su calidad, su eficacia en la ejecución, que resuelvan problemas específicos, que sean generales, abstractas e impersonales. El asesor del servicio parlamentario de carrera tiene la obligación de garantizar que las iniciativas presentadas cumplan con los elementos indispensables para su función, dichos elementos pueden ser:

- Que exista un problema real a legislar.

- Determinar la competencia, estatal o extraestatal.

- Necesidad de una Ley.

- Redacción con elementos técnicos necesarios

- Estudios de impacto (económico, social, ambiental, cultural, entre otros, según sea el caso).

- Considerar todos los elementos a legislar evitando vacíos legales.

- Derecho comparado.

En el siguiente cuadro, ejemplificaré un problema de redacción que conduce a la confusión en una iniciativa y que de ser aprobada generaría un problema.

\begin{tabular}{|l|l|l|}
\hline \multicolumn{1}{|c|}{ Tema } & \multicolumn{1}{|c|}{ Mala redacción } & \multicolumn{2}{c|}{ Redacción adecuada } \\
\hline $\begin{array}{l}\text { Computadoras para todos } \\
\text { lostudiantes de } \\
\text { educación básica. }\end{array}$ & $\begin{array}{l}\text { Artículo. El Estado proveerá } \\
\text { de computados a todos } \\
\text { niños, niñas y adolescentes } \\
\text { de } 6 \text { a } 18 \text { años, para } \\
\text { coadyuvar en la educación. }\end{array}$ & $\begin{array}{l}\text { Artículos Estado proveerá de } \\
\text { equipos de cómputo a los } \\
\text { estudiantes de educación básica } \\
\text { en la modalidad primaria, } \\
\text { secundaria y preparatoria, que } \\
\text { resulten seleccionados del } \\
\text { resultado de un estudio } \\
\text { socioeconómico, que sus } \\
\text { viviendas cuenten con servicio } \\
\text { de electricidad doméstica y con } \\
\text { un promedio general de }\end{array}$ \\
\hline
\end{tabular}


aprovechamiento de 8.5 como mínimo.

En el apartado de mala redacción, nos encontramos con una propuesta de iniciativa que no cuenta con los elementos suficientes para su ejecución, ya que no todos los niños, niñas y adolescentes del Estado de 6 a 18 años estudian, no todos cuentan con servicio de electricidad doméstica y algunos de ellos dejaran la escuela para dedicarse al trabajo físico. El impacto económico al pretender dotar de equipo de cómputo a todos los niños, niñas y adolescentes sería alto y en algunos casos un gasto innecesario.

En el apartado de redacción adecuada, nos encontramos con una iniciativa que cuenta con elementos que determinan su viabilidad, ya que en la investigación de dicha propuesta, se consideraron datos certeros y objetivos que reducen el campo de población beneficiada. El impacto económico se ve también reducido y genera una buena inversión social, además de incentivar a los estudiantes a continuar con sus estudios hacia la profesionalización.

Lo anterior, lamentablemente refleja una situación cotidiana en nuestro marco jurídico, lo que resulta en leyes obsoletas e inoperantes, que pueden atrasar o conflictual procesos administrativos o judiciales. Que desgastan a la población y no les brindan certeza jurídica. Es importante que nuestros legisladores conozcan a la perfección el sistema parlamentario y que cuenten con un equipo profesional especializado que les ayude a tomar las mejores decisiones y conducir con honorabilidad la labor legislativa.

\section{FUENTES DE CONSULTA}

ALCÁNTARA SÁEZ, M., El oficio de político, Madrid, TECNOS, 2012.

ALCÁNTARA SÁEZ, M., La carrera política y el capital político, 2017, Convergencia, vol. 24, (no.73), págs. 187-204 doi:105/10550008008. https://www.redalyc.org/articulo.oa?id=10550008008.

ALONSO DE ANTONIO, J.A. y ALONSO DE ANTONIO, Á.L., Introdución al derecho parlamentario. Madrid, Dykinson, 2002.

ARIAS-SCHREIBER, F., \& PEÑA JUMPA, A. (2015). La nueva teoría de la legislación. IUS ET VERITAS, 24(51), 196-206. Recuperado a partir de http://revistas.pucp.edu.pe/index.php/iusetveritas/article/view/15695.

ATIENZA, M., Contribución a una teoría de la Legislación, Madrid, Civitas, 1997.

ARTEAGA NAVA, E., Tratado de Derecho Constitucional. México, Oxford University Press, 1999. 
BASTIAT, F., La Ley. México, CISLE, 2003.

BÁTIZ VÁZQUEZ, B., Ética del legislador. [aut. libro] Javier SALDAÑA SERRANO. Ética jurídica (Segundas jornadas). México, Flores, 2015, págs. 127-134.

- Teoría del Derecho Parlamentario. México, Oxford, 1992. http://www.diputados.gob.mx/bibliot/publica/otras/libro1/conte.htm.

BENTHAM, J., Nomografía o el arte de redactar leyes. México, SENADO DE LA REPÚBLICA, 2009.

Berlín VAlenzUelA, F., Derecho Parlamentario. México, Fondo de Cultura Económica, 2000.

CABADA HUERTA, Marineyla., La Naturaleza del Acuerdo Político. 2008, Quórum Legislativo, (no.88), págs.

93-130.

file:///C:/Users/Usuario/Downloads/acuerdo\%20parlamentario.pdf.

CAMACHO VARGAS, J.L., El Congreso Mexicano. México, CÁMARA DE DIPUTADOS, 2013.

CARBONELL, M., Diccionario de derecho constitucional, México, Porrúa-UNAM, 2003.

CARPIZO, J., Caracteristicas esenciales del sistema presidencial e influencias para su isntauración en América Latina. 2006, Scielo, Vol. 39 (no.115), págs. 57-91 ISSN 24484873. Recuperado en 08 de marzo de 2020, de http://www.scielo.org.mx/scielo.php?script=sci_arttext\&pid=S0041$\underline{86332006000100002 \& \operatorname{lng}=\text { es\&tlng=es. }}$

CERVANTES GÓMEZ, J.C., Derecho Parlamentario, Organización y Funcionamiento del Congreso, México, Serie Roja, 2012.

CHÁVEZ HERNÁNDEZ, E., EL DERECHO PARLAMENTARIO ESTATAL MEXICANO. Análisis y Propuesta de Reforma. México : Instituto de Investigaciones Jurídicas, 2016. págs. 31-59. https://archivos.juridicas.unam.mx/www/bjv/libros/9/4236/14.pdf.

CRUZ VILLALOBOS, Osvaldo., El servicio Profesional de Carrera y los cambios en la Gestión Pública de México, México, Instituto de Administración Pública del Estado de México, 2009.

ERAÑA SÁNCHEZ, M., Derecho Parlamentario Orgánico, Claves para ser un buen legislador en México. México, Porrúa, 2013.

GARITA, A., La Práctica Parlamentaria, México, Senado de la República, 2016.

HURTADO CISNEROS, M., La calidad de la democracia y la necesidad del fortalecimiento del Poder Legislativo local. [aut. libro] Biblioteca Mexiquense del 
Bicentenario. Estudios en torno al Podel Legislativo. Toluca: Consejo Editorial de la Administración Pública Estatal, 2010.

MADERO ESTRADA, J.M., Diccionario Legislativo. Tepic : Universidad Autónoma de Nayarit, 2000.

MARTÍNEZ PUÓN, R., La profesionalización de la Función Pública: ideas para Latinoamérica. Mérida, Venezuela : Colecciones de Gobierno y Administración Pública del Gigep, 2003.

MÁTTAR, J., Desafíos de un buen gobierno: La profesionalización de la función pública. Tepoztlán: Centro Tepoztlán Víctor L. Urquidi, AC, 2018. http://www.foroconsultivo.org.mx/proyectos_estrategicos/img/8/34.pdf.

MAURER, L.M., El poder del Parlamento: Congreso y Políticas públicas en España. Madrid : Centro de Estudios Políticos y Constitucionales, 2008.

MORA-DONATTO, C., Constitución, Congreso, Legislación y Control, Coordenadas para Legisladores en los Tiempos de Reelección. México : Instituto de Investigaciones Jurídicas, UNAM, 2015.

- El Parlamento de México. Historia estructura y funciones. México : Instituto de Investigaciones Jurídicas $\quad$ UNAM, 2019. https://archivos.juridicas.unam.mx/www/bjv/libros/12/5638/11.pdf.

- Las comisiones parlamentarias de investigación como órganos de control político. México : CÁMARA DE DIPUTADOS, 1998.

- Teoría de la Legislación y Técnica Legislativa. México : Instituto de Investigaciones Jurídicas UNAM, 2012.

- Urge rediseñar el servicio civil de carrera del Congreso mexicano. 2008, Cuestiones constitucionales (no.

19). http://www.scielo.org.mx/scielo.php?script=sci_arttext\&pid=S1405-91932008000200007.

- TREINTA AÑOS de investigaciones parlamentarias en México. México : Instituto de Investigaciones Jurídicas, UNAM, 2013.

MURO RUIZ, Eliseo., Algunos elementos de técnica legislativa. México : Instituto de Investigaciones Jurídicas, UNAM, 2008.

ORDAZ SÁNCHEZ, G., La evolución de los Principios Parlamentarios y su vinculación con las Prácticas Parlamentarias (Representación, Derecho a la Información e Igualdad), 2017, Instituto de investigaciones Jurídicas, pág. 34. http://aldf.gob.mx/archivo7d9d911ae01bf7018028dc758dc65eb8.pdf. 
PARDO, M.C., El Servicio Civil de Carrera para un mejor desempeño de la Gestión Pública. México: Serie: Cultura de la Rendición de Cuentas, 2006.

PEDROZA DE LA LLAVE, S.T., Las fuentes formales del derecho parlamentario y su normatividad constitucional en México. 2012, Cuestiones Constitucionales, págs. 169-220. $\begin{array}{llllll}\text { Recuperado en } 08 \text { de de } & 020 \text {, de }\end{array}$ http://www.scielo.org.mx/scielo.php?script=sci_arttext\&pid=S140591932012000100006\&lng=es\&tlng=es.

PEDROZA DE LA LLAVE, S.T., Notas actuales sobre el Derecho Parlamentario en los sistemas de Gobierno, de Asamblea, Parlamentario, Presidencial y el semipresidencial o semiparlamentario. 2011, Revista de la Facultad de Derecho de México. Vol 61, No 255., págs. 353-389. http://www.revistas.unam.mx/index.php/rfdm/article/view/30272/28119.

PORTALIS, J.-É.-M., Discurso preliminar sobre el proyecto de Código Civil. Madrid: UNIVERSIDAD CARLOS III DE MADRID, 2014.

SALDAÑA SERRANO, J., Ética jurídica. México : Instituto de Investigaciones Jurídicas UNAM, 2015. https://archivos.juridicas.unam.mx/www/bjv/libros/8/3970/24.pdf.

SÁNCHEZ GÓMEZ, E., Técnica Legislativa. [aut. libro] Cecilia MORA-DONATTO. Teoría de la Legislación y la Técnica Legislativa. Nayarit: Instituto de Investigaciones Jurídicas, 2012. https://archivos.juridicas.unam.mx/www/bjv/libros/7/3201/5.pdf.

SANTAOLALlA LÓPEZ, F., Derecho Parlamentario Español. Madrid, Espasa Calpe, 1990.

SARMIENTO, X.A., La función pública parlamentaria y su plasmación legislativa en Galicia. 2009, Anuario de Derecho Parlamentario.

TOSI, Silvano., Derecho Parlamentario. México : Miguel Ángel Porrúa, 1996.

VALENCIA ESCAMILLA, L., Élites parlamentarias y profesionalización legislativa en México, 2009, El Cotidiano (no.155).

https://www.researchgate.net/publication/45087378_Elites_parlamentarias_y_profesionaliz acion_legislativa_en_Mexico. 